\title{
Gıda Tankeri için AISI 304 Paslanmaz Çeliğin TIG Kaynağının İncelenmesi
}

\author{
Yunus Bertan ${ }^{1}$, Eren Y1lmaz ${ }^{2,3 *}$ \\ 1* Sakarya Uygulamalı Bilimler Üniversitesi, Teknoloji Fakültesi, İmalat Mühendisliği Bölümü, Sakarya, Türkiye, (ORCID: 0000-0002-5712-777X), \\ bertan.yunus@gmail.com \\ 2 Sakarya Uygulamalı Bilimler Üniversitesi, Arifiye Meslek Yüksekokulu, Kaynak Teknolojisi Programı, Sakarya, Türkiye (ORCID: 0000-0001-7264-2588), \\ erenyilmaz@subu.edu.tr \\ ${ }^{3}$ Sakarya Uygulamalı Bilimler Üniversitesi, Malzeme ve Üretim Teknolojileri Uygulama ve Araştırma Merkezi, Sakarya, Türkiye
}

(Uluslararası Araştırma-Geliştirme ve Tasarım Konferansı - 15-18 Aralık 2021)

(DOI: $10.31590 /$ ejosat.1039236)

\begin{abstract}
ATIF/REFERENCE: Yunus, B., Eren Y. (2021). Gıda Tankeri için AISI 304 Paslanmaz Çeliğin TIG Kaynağının İncelenmesi. European Journal of Science and Technology, 622-626.

Öz

Bu çalışmada, kara yollarında kullanılan AISI 304 paslanmaz çeliğinden imal edilen gıda tankerlerinin gövde birleştirmeleri, AISI 316LSi ilave metal kullanılarak Tungsten Inert Gaz kaynak yöntemi ile oluk pozisyonunda çift taraflı olarak uygulanmıştır. Kaynaklı bağlantının mikroyapısı optik mikroskop ve taramalı elektron mikroskobu ile incelenmiştir. Kaynak bölgesinin mikroyapısı östenit ve delta ferrit fazlarından oluşmuştur. Kaynaklı bağlantıda oluşması muhtemel süreksizlikler sıvı penetrant testi ve radyografik muayene ile incelenmiştir. Mekanik testler için sertlik ve çekme testleri gerçekleştirilmiştir. Ana metal, 1sıdan etkilenen alan ve kaynak bölgesinden alınan sertlik değerleri yaklaşık $200 \mathrm{HV}$ ölçülmüştür, bu üç bölgenin sertliği biririne yakın elde edilmiştir. Kaynaklı bağlantının çekme mukavemeti $580 \mathrm{MPa}$ olarak belirlenmiştir. Dolayısıyla seçilen kaynak parametrelerinin optimum olduğu mikroyapı incelemeleri, tahribatsız muayeneler ve mekanik testler ile görülmüştür.
\end{abstract}

Anahtar Kelimeler: TIG kaynağı, kaynak parametreleri, nüfuziyet, östenitik paslanmaz çelik.

\section{Investigation of TIG Welding of AISI 304 Stainless Steel for Food Tanker}

\begin{abstract}
In this study, the joints of food tankers made of AISI 304 stainless steel used on highways were applied on both sides by Tungsten Inert Gas welding method using AISI 316LSi additive metal. The microstructure of the welded joint was investigated by optical microscope and scanning electron microscope. The microstructure of the weld zone consists of austenite and delta ferrite phases. Possible discontinuities in the welded joint were examined by liquid penetrant test and radiographic examination. Hardness and tensile tests were carried out for mechanical tests. The hardness values taken from the base metal, heat affected area and weld zone were measured at approximately $200 \mathrm{HV}$, the hardness of these three zones was obtained close to one. The tensile strength of the welded joint was determined as $580 \mathrm{MPa}$. Therefore, it has been seen that the selected welding parameters are optimal by microstructure investigations, non-destructive examinations and mechanical tests.
\end{abstract}

Keywords: TIG welding, welding parameters, penetration, austenitic stainless steel.

\footnotetext{
*Sorumlu Yazar: erenyilmaz@subu.edu.tr
} 


\section{Giriş}

Gıda tankerleri, taşıdığı gıdanın dolumdan boşaltım anına kadar duyusal özelliklerini koruyan, tasarım hesaplamalarına uygun kalınlıklarda, silindirik kesitte, tahrikli ve akarına boşaltım yapabilen, östenitik paslanmaz çelik malzemeden üretilen gövde yapısına sahip ve "Tehlike Analizi ve Kritik Kontrol Noktaları" (HACCP) mevzuatına uygun tasarlanan motorsuz karayolu araçlarıdır. Gıda endüstrisi depolama tanklarında östenitik paslanmaz çelik önemli bir malzemedir [1,2].

Östenitik paslanmaz çelik çok iyi korozyon direncine sahiptir, yüksek mekanik özellikler içerir, düşük ve yüksek sıcaklıklarda kullanılabilir, şekillendirilmesi kolay ve güzeldir, bu nedenle geniş bir kullanım alanına sahiptir. Paslanmaz çelikler arasında en yaygın kullanılanı \%70 oranı ile östenitik paslanmaz çeliktir. Östenitik paslanmaz çelikte en yaygın kullanılan alaşım AISI 304 yüksek kaliteli östenitik paslanmaz çeliktir[3]. Fiyatına kıyasla AISI 304 yüksek kaliteli östenitik paslanmaz çelik, kimyasal bileşimi, mekanik özellikleri, kaynaklanabilirliği ve korozyon ve oksidasyon direnci nedeniyle tercih edilir. $\mathrm{Bu}$ paslanmaz çelik kalitesi, piyasada kolayca bulunabilmesi, şekillendirilmesi ve kaynaklanması kolay olduğu için en popüler paslanmaz çelik kalitelerinden biridir. AISI 304 en uygun maliyetli paslanmaz çeliklerden biridir. Özellikle hemen her alanda günlük hayatın bir parçası haline gelmiştir. Bu nedenle bu çeliklerin genellikle birbirleriyle veya kullanımlarına göre farklı kalitedeki çeliklerle kombine edilmesi gerekir.

Östenitik paslanmaz çeliği kaynağında dikkat edilmesi gereken konu, oluşabilecek sıcak çatlama ve sigma fazı oluşumu riskidir. Bir kaynak elektrotu seçerken, sıcak çatlama ve sigma fazı oluşumu riskinden kaçınılabilmesi için minimum kimyasal bileşim ile yapılmalıdır. Sıcak çatlama, kükürt $(\mathrm{S})$ ve fosfor $(\mathrm{P})$ gibi elementlerden oluşan düşük erime noktalı metalik bileşikler nedeniyle oluşur ve tane sınırlarında güçlü bir topaklanma eğilimi gösterir. $\mathrm{Bu}$ bileşikler kaynak dikişinde veya 1sıdan etkilenen bölgede bulunurlarsa, tane sınırlarına yayılırlar ve kaynak dikişi soğudukça ve çekme gerilimi oluştukça çatlakların oluşmasına neden olurlar. Östenitik paslanmaz çeliklerin kaynağında sıcak çatlak oluşumunu önlemek için kaynak işleminden sonra oluşacak kaynak dolgusu yapısındaki ferrit içeriğinin \%4'ten fazla olması tavsiye edilir. Çünkü ferrit, kükürt ve fosfor bileşimlerini kontrol eden ve ferritik östenitik bir yapıya sahip olan tane sınırları oluşturarak sıcak çatlakların oluşmasını engeller [6]. Sigma fazı çok sert (700800 HV), anti-manyetik ve kırılgan bir intermetalik bileşiktir. Bileşimi yaklaşık olarak $\mathrm{RCr}$ ve $\mathrm{HFe}$ içerir ve $550{ }^{\circ} \mathrm{C}$ ile $925^{\circ} \mathrm{C}$ arasındaki sıcaklıklarda oluşur. Östenitik çeliklerde bu fazın oluşması için östenitik yapıda ferrit bulunması gerekir. Soğuk deformasyon, niyobyum, molibden ve silikon gibi elementlerin varlığı sigma fazının oluşumunu destekler. Sigma fazı, çeliğin deformasyon kapasitesini ve darbe dayanımını azalttığı için istenmeyen bir durumdur. Sigma fazı, tek tip tavlama ile veya alttaki kaynak bölgesinde ferrit miktarının tutulmasıyla ortadan kaldırılabilir ve bu alanın özellikleri üzerinde olumsuz bir etki yaratması önlenebilir [4].

TIG (Tungsten Inert Gas) kaynağ1, estetik görünüm ve montaj kalitesi sunan, paslanmaz çeliklerin birleştirilmesine uygun modern bir kaynak yöntemidir. Bu kaynak yönteminde, tungsten elektrot ile birleştirilecek metal arasında bir elektrik ark1 oluşturulur. Ark bölgesi, inert gazlar veya gaz karışımları ile çevrenin olumsuz etkilerinden korunur. Kaynak sırasında tungsten elektrot yüksek bir sıcaklığa ulaştığında arkın devamı e-ISSN: 2148-2683 için gerekli elektron emisyonu sağlanır. TIG kaynak yönteminin diğer birleştirme yöntemlerine göre birçok avantajı olmakla birlikte bazı dezavantajları da bulunmaktadır. Özellikle tek kaynakta yapılan kaynak işlemi yeterince nüfuz etmediğinden kalın kesitli parçalar için bunun uygun bir işlem olmadığı düşünülmektedir. Bununla birlikte, ana metalin kimyasal bileşimine bağlı olarak kaynak dikişine karşı bir hassasiyet vardır. Diğer kaynak yöntemleriyle karşılaştırıldığında, daha yavaş kaynak hızları genellikle verimliliği düşürür[5, 6]. Her kaynak yönteminde olduğu gibi TIG kaynağında da en yüksek kaynak kalitesini elde etmek için her malzeme için uygun kaynak parametrelerinin belirlenmesi ve kaynak sirasında bu parametrelere uyulması gerekmektedir. TIG kaynağında kullanılan kaynak akımı, kaynak gerilimi, kaynak hızı, koruyucu gaz türü, akış miktarı, ark uzunluğu, kaynak kutbu ve bağlantı tasarımı gibi kaynak parametrelerinin TIG kaynağının performansını büyük ölçüde etkilediği bilinmektedir. Kaynak işleminde uygulanan parametreler, kaynak banyosunun geometrisini ve metalin mekanik özelliklerini büyük ölçüde etkiler. $\mathrm{Bu}$ parametreler arasında kaynak akımı en önemli değişkenlerden biridir ve kaynak akımının değişimi, penetrasyon derinliğini, kaynak genişliğini, 1sı girdisini, metal çökelme oranını vb. kaynağın tipini ve kalitesini etkiler. Darbeli ark kullanımı durumunda, kaynak sırasında akım ve penetrasyon miktarı maksimuma çıkarken, kaynak metali 1sı girişi minimum değerlerde kalır [7,8]. Sonuç olarak ince kesitli parçalarda optimum özellikler sağlayan bağlantılar elde edilecektir. Şimdiye kadar birçok araştırmacı, farklı kaynak yöntemleriyle yapılan birleştirmelerde seçilen parametrelerin nüfuziyet üzerindeki etkisini araştırmıştır[8-11]. Kaynak akımı ve hızı gibi kaynak parametreleri, kaynak işlemindeki diğer değişkenlerle karşılaştırıldığında, etkilerinin oldukça karmaşık olduğu düşünülmektedir. Kaynak akımının değişimi, kaynak banyosuna sağlanan 1sı miktarını doğrudan etkiler. $\mathrm{Bu}$ nedenle kaynak geometrisi, kaynak banyosuna verilen 1s1 girdisine ve 1S1 dağılımına bağlı olarak değişir [12,13]. Aynı kimyasal bileşime sahip paslanmaz çeliklerin kaynak değişkenlerindeki küçük farklılıklar bile kaynak banyosundaki sıvının akış modelini etkiler[11]. Koruyucu gazın bileşimindeki farklılığın kaynak sırasında nüfuz etme üzerinde önemli bir etkiye sahip olduğu bilinmektedir[8, 9, 10].

Bu çalışmada AISI 304 paslanmaz çeliği AISI 316LSi ilave metaliyle TİG kaynağı kullanılarak birleştirilmiştir. Bu kaynağın gıda tankeri için kullanılabilirliği, mikroyapı incelemesi, mekanik testler ve tahribatsı muayene yöntemleri ile incelenmiştir.

\section{Materyal ve Metot}

\subsection{TIG kaynağı işlemi ve analizler}

Uygulamada kullanılan kaynak parametreleri Tablo 1'de özetlenmektedir. Kaynaklı birleştirmede ana malzeme olarak 100x40x2 mm ebatlarında AISI 304 östenitik paslanmaz çelik levhalar ve ilave metal olarak 316LSi malzemesi kullanılmıştır. $\mathrm{Bu}$ malzemelerin kimyasal kompozisyonları Tablo 2'de verilmiştir. Kaynak nüfuziyetini arttırmak ve dikiş görüntüsünü iyileştirmek için oluk pozisyonunda (PA) çift taraflı alın kaynağı gerçekleştirilmiştir. Şekil 1'de gıda tankeri gövdesi, kaynak bölgeleri ve kaynaklı numune göreseli yer almaktadır. TIG kaynağında MERKLE marka kaynak makinesi kullanılmıştır. Kaynak işlemi sonrası her iki yüzey, bir eksen etrafında homojen olarak sıralanmış $150 \mathrm{~mm}$ çapında ve 240 kum zımpara ile temizlenmiştir. 
Kaynak işlemi sonrası, ana metal, 1sı tesiri altındaki bölge (ITAB) ve kaynak metali bölgesini içeren kesit metalografik olarak hazırlanıp, oksalik asit çözeltisi ile elektrolitik dağlanmıştır ve optik mikroskop (OM, Nikon Eclipse L50), taramalı elektron miroskobu (SEM, Jeol JSM 6060LV) ve enerji dağılım spektrometresi (EDS) analizleri ile incelenmiştir. Malzeme yüzeyinde ve iç kısmında oluşması muhtemel süreksizliklerin incelemesi için sırasıyla sıvı penetrant testi $(\mathrm{PT})$ ve radyografik muayene (RT) gerçekleştirilmiştir. Metalografik inceleme yapılan yüzeyden $200 \mathrm{~g}$ yük ve $10 \mathrm{~s}$ parametrelerinde sertlik ölçümleri alınmıştır. İlave olarak TS EN ISO 4136 standartına göre çekme testi gerçekleştirilmiştir.

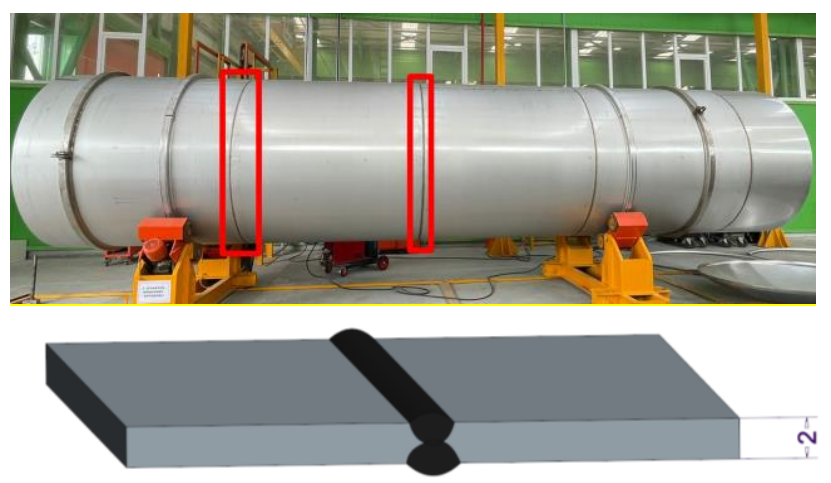

Şekil 1. Glda tankeri ve kaynak numunesi görseli

Tablo 1. Kaynak parametreleri

Kaynak Parametreleri

Kaynak yöntemi

Manuel TIG 141

Kaynak teli malzemesi

316LSi

Tel çapı (mm)

$\operatorname{Akım}(\mathrm{A})$

Kaynak hızı (cm/dk)

Koruyucu gaz

Saf Argon

Tablo 2. Ana metal ve ilave metalin kimyasal kompozisyonu

\begin{tabular}{|c|c|c|c|c|c|c|}
\hline & \multicolumn{7}{|c|}{ Kimyasal birleşim (\%) } \\
\cline { 2 - 7 } & $\mathrm{C}$ & $\mathrm{Si}$ & $\mathrm{Mn}$ & $\mathrm{Cr}$ & $\mathrm{Ni}$ & $\mathrm{Mo}$ \\
\hline AISI 304 & 0.07 & 1 & 2 & $17.5-19.5$ & $8-10.5$ & - \\
\hline AISI 316LSi & 0.01 & 0.8 & 1.8 & 18.5 & 12.20 & 2.5 \\
\hline
\end{tabular}

\section{Araştırma Sonuçları ve Tartışma}

Şekil 2'de kaynaklı bağlantının optik mikroyapı görüntüleri yer almaktadır. Kaynak bölgesi, ergime sınırı, ITAB bölgesi açık bir şekilde Şekil 2a'da gözlenmektedir. Kaynak bölgesinde herhangi bir MnS gibi kalıntılar veya herhangi bir makro süreksizlikler gözlenmemiştir. Kaynak bölgesi açık renkli (östenit) ve koyu renkli (delta ferrit) yapılar olmak üzere iki fazdan oluşmuştur (Şekil 2b). Ergime sınırına yaklaştıkça 1s1 transferi yönünde yönlenmiş yapılar görülmektedir. ITAB bölgesinde ise 1sının etkisi ile AISI 304 çeliğine ait irileşen taneler oluşmuştur. Şekil 2c'de ise ana metale ait östenitik yap1 görülmektedir. Buradaki tane boyutları, ITAB'dan daha incedir. Kaynak bölgesinin farklı alanlarında soğuma hızlarına göre tane şekilleri ve delta ferrit miktarı değişim göstermiştir. Ancak iki taraflı kaynak yapılması, bu değişimi literatürdeki çalışmalara kıyasla bastırmıştır. Kaynak bölgesinde çok hızlı soğumadan oluşabilecek martenzit fazı gözlenmemiştir. Ayrıca yapıdaki delta ferrit varlığının olması ve herhangi bir $\mathrm{MnS}$ inklüzyonun bulunmaması çok düşük soğuma hızının yaşanmadığını göstermektedir. Özetle ideal bir kaynak soğuma işlemi yapılmıştır.
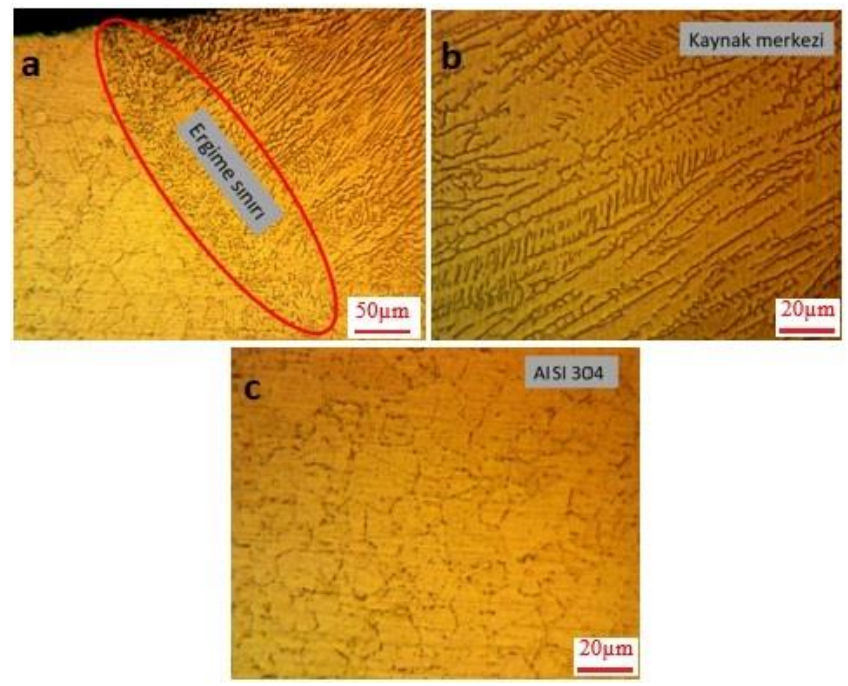

Şekil 2. a) Kaynaklı bağlantının, b) kaynak metalinin ve c) ana malzemenin optik mikroyapisı

Kaynak metali bölgesi SEM ve EDS analizleri ile daha detaylı incelenmiştir. Kaynak metalinin ortasından alınan görüntüye göre, ITAB bölgesine kıyasla nispeten eş eksenli yap1 gözlemlenmiştir (Şekil 3). Kaynak bölgesinde, optik mikroyapı görüntülerine benzer olarak iki fazın olduğunu gösteren açık 
renkli ve koyu renkli bölgeler oluşmuştur. Açık renkli bölgede (Şekil 4a), koyu renkli bölgeye (Şekil 4b) göre östenit yapıcı element miktarı (Ni) azalırken, ferrit yapıcı element (Cr, Mo) miktarı artmıştır. Buda ana fazın östenitten, çizgisel görünen bölgelerin ise delta ferritten oluştuğunu kanıtlamaktadır.

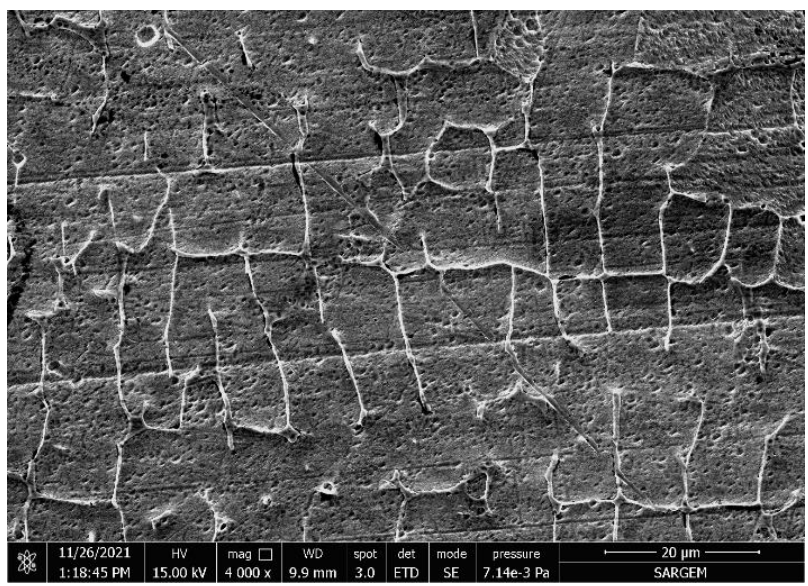

Şekil 3. Kaynak metalinin SEM görüntüsü
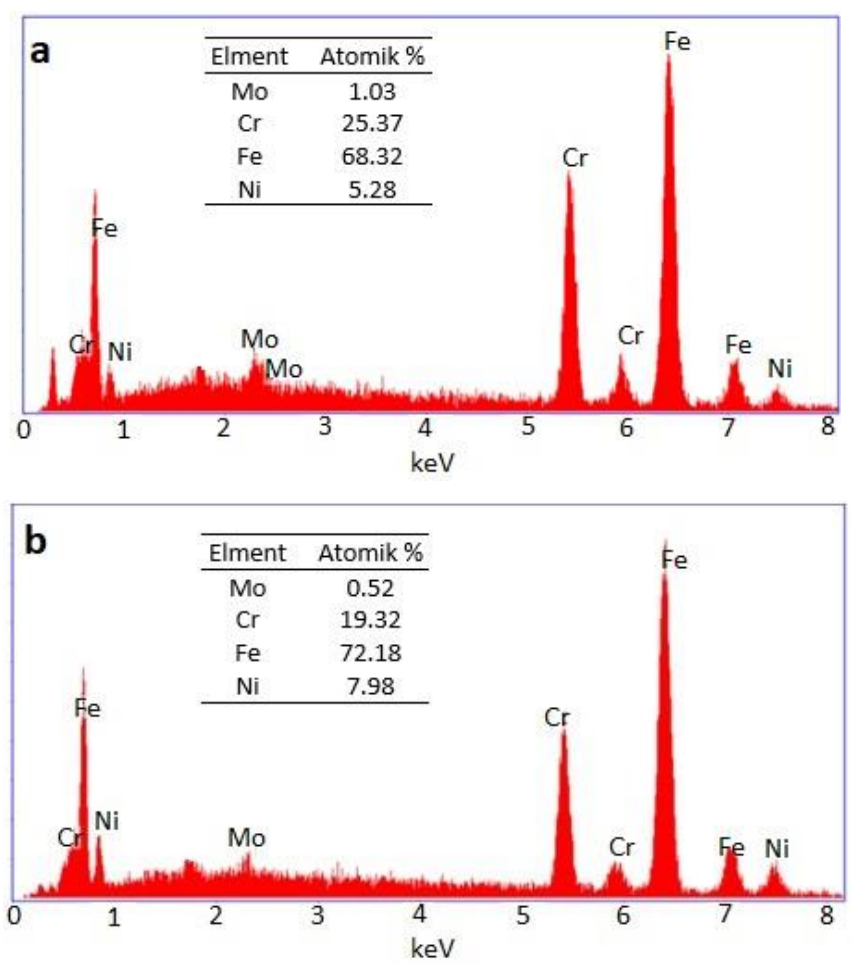

Şekil 4. Kaynak metali bölgesinin EDS analizi

Kaynak sonrası PT testi ile yüzey süreksizlikleri incelenmiştir. Ön temizlik sonrası penetrant yüzeye uygulanmıştır (Şekil 5a), penetrasyon süresi beklenildikten sonra ara temizlik yapılmıştır ve geliştirici yüzeye tatbik edilmiştir (Şekil 5b). Süreksizliği belirten herhangi bir penetrant kusmasına rastlanmamıștır. Kaynaklı bağlantının iç kısmındaki hacimsel süreksizliklerin belirlenmesi için $\mathrm{X}$-1şını ile radyografik test yapılmıştır (Şekil 5c). Yoğunluk farkı ve kalınlık farkı nedeniyle kaynak metali bölgesi aydındık görünmektedir. Süreksizliği belirten herhangi bir bulgu gözlenmemiştir.
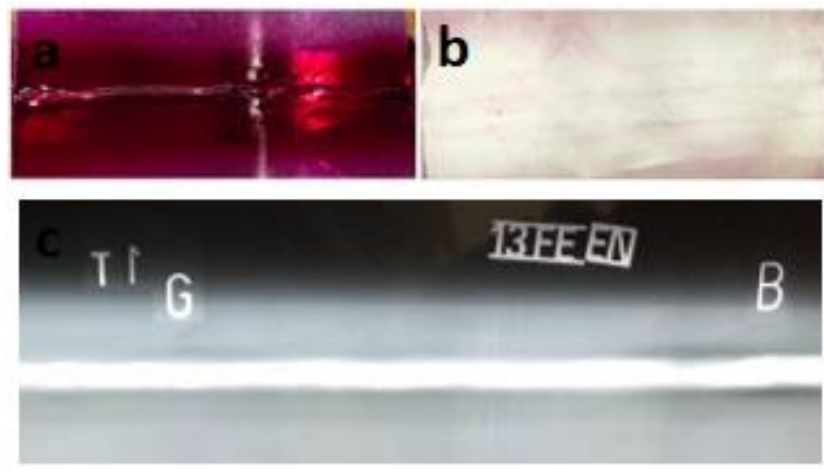

\section{Şekil 5. Kaynaklı bağlantının a), b) Sivı penetrant testi, c) Radyografik filmi}

Sirasiyla ana metal, ITAB bölgesi ve kaynak metali bölgesinin sertlik değerleri ortalama $20 \mathrm{O} \mathrm{HV}, 194 \mathrm{HV}$ ve $204 \mathrm{HV}$ ölçülmüştür. Üç bölge için de değerler birbirine yakındır. ITAB bölgesindeki sertliğin hafif düşüşünün nedeni tane irileşmesi iken, kaynak bölgesindeki sertliğin hafif artışının nedeni mikroyapıdaki delta ferrit fazı varlığıdır. Sonuçlar literatürle uyumludur [9].

Kaynak soğuma hızına etki eden etmenler delta ferrit miktasını değiştirir ve sonuçta mekanik özellikler etkilenir [10]. Kaynaklı bağlantının çekme mukavemeti ortalama $580.7 \mathrm{MPa}$ tespit edilmiştir. Bu sonuç, östenitik paslanmaz çeliği kaynağı ile ilgili çalışmalar ile eşleşmektedir [9].

\section{Sonuç}

G1da tankeri üretimindeki AISI 304 paslanmaz çeliği kaynağı TIG yöntemi ile başarıyla uygulanmıştır. Tahribatsız muayene incelemeleri sonucunda herhangi bir yüzeysel veya hacimsel süreksizlik tespit edilmemiştir. Mikroyapı incelemelerine göre kırılganlık yaratacak martenzitik dönüşüm veya inklüzyonlar gözlenmemiştir. Ayrıca kaynak bölgesi boyunca dağılan delta ferrit miktarları neredeyse homojen gözlenmiştir. ITAB bölgesinde 1sı etkisiyle beklendiği gibi tane büyümesi yaşanmıştır. Kaynaklı levha kesiti boyunca sertlik dağılımı birbirine yakın elde edilmiştir. Bu da mekanik özellikler için avantaj sağlamaktadır. Seçilen kaynak tekniği ve parametreleri optimum sonuçlar vermiştir.

\section{Teșekkür}

Yazarlar, bu çalışmada kaynak işlemlerindeki desteklerinden dolayı Tırsan Treyler A.Ş. şirketine teşekkür eder.

\section{Kaynakça}

Smith, W.F.(2000). Paslanmaz çelikler, Mühendislik Alaşımlarının Yapı ve Özellikleri.

Odabaş, C. (2004). Paslanmaz çelikler, temel özellikleri, kullanım alanları, kaynak yöntemleri.

Aran, A., Temel, M.A. (2004). Paslanmaz çelikler

Dikicioğlu, A. (2006). Kaynaklı imalat ve tasarım ders notları

Modenesi, P.J., Apolınaarı, E.R., Pereıra, I.M.(2000). TIG welding with single-component fluxes. Journal of Materials Processing Technology, 99, 260-265. 
Gürcan, M. (1987). TIG kaynağı.

Eşme, U. (2006). Effect of pool geometry on the quality of TIG welded joints.

Kım, I.S., SON, I.G., KIM, J.Y., KIM, O.S. (2003). A study on relationship between process variables and bead penetration for robotic $\mathrm{CO}_{2}$ arc welding. Journal of Material Processing Technology, 136, 139-145.

Tümer, M., Y1lmaz, R. (2016). Characterization of microstructure, chemical composition, and toughness of multipass welded joint of austenitic stainless steel AISI316L. International Journal of Advanced Manufacturing Technology, 87, 2567-2579.

Shanpıng, L., Hidetoshi, F., Kiyoshi, N. (2005). Influence of welding parameters and shielding gas composition on GTA weld shape. ISIJ International, 45, 66-70.

Aıdun, D.K., Martin, S.A. (1997).Effect of sülfür and oxygen on weld penetration of high-purity austenitic stainless steels. Journal of Materials Engineering and Performance, 6, 496502.

Valiente Bermejo, M.A., Karslsson, L., Svensson L.E., Hurtig., K., Rasmuson, H., Frogdigh, M., Bengtsson, P. (2005). Effect on shielding gas on welding performance and properties of duplex and superduplex stainless steel welds. Weld World, 59, 239-249.

Kaçar, R., Baylan, O. (2004). An investigation of microstructure/property rleationships in dissimilar welds between martensitic and austenitic stainless steels. Materials Design, 25, 317-329. 